\title{
Food Poisoning Prevention Monitoring System based on the Smart RFID Tag System
}

\author{
Ki-Hwan Eom, Chang Won Lee, Nghia Truong Van, Kyung Kwon Jung, \\ Joo Woong Kim and Woo Seung Choi \\ Department of Electronics and Electrical Engineering \\ Dongguk University, Seoul, Korea, \\ Korea Electronic Technology Institute, Gachon University \\ kihwanum@dongguk.edu
}

\begin{abstract}
Food poisoning that can happen commonly, a little caution can be prevented in advance, but the average consumer can not know whether the poisoning infection of food. While there are many factors affecting food poisoning typically changes in temperature and humidity, and monitoring temperature and humidity variability during transport and storage is very important. So we proposed the food poisoning prevention monitoring system based on the smart RFID tag system. Proposed system consists of RFID tag, temperature and humidity sensor, sensor interface, RFID reader, and server. In order to verify the effectiveness of the proposed system, we performed experiments on the tofu. Proposed system measures the temperature and humidity using the smart RFID tag. The measured information can be calculated according to food poisoning index with four grade, interest, caution, warning, risk, and is monitored. The proposed system confirms usefulness through experiments.
\end{abstract}

Keywords: Food poisoning prevention monitoring system, Smart RFID Tag, Temperature sensor, Humidity sensor, Sensor interface

\section{Introduction}

According to WHO, the human health harm factors that is occurred most often in the world is the disease which is caused by the contaminated food as food poisoning. A food contamination can occur in the production process, but also a large part caused by the careless food handling due to various causes when a food is transporting and storing [1]. Food poisoning that can happen commonly, a little caution can be prevented in advance, but the average consumer can not know whether the poisoning infection of food. While there are many factors affecting food poisoning typically changes in temperature and humidity, and monitoring temperature and humidity variability during transport and storage is very important.

In this paper, we propose the food poisoning prevention monitoring system based on the smart RFID tag system that prevent food poisoning due to food contamination that can occur during the transportation and storage of food. Proposed system consists of RFID tag, temperature and humidity sensor, sensor interface, RFID reader, and server. The proposed system can prevent food poisoning through food status monitoring as the temperature and humidity data measured of surrounding environment during the transportation and storage of food in real time by $900 \mathrm{Mhz}$ smart RFID sensor tag, which is contained temperature and humidity sensor, is applied to food poisoning index that is provided the Food and Drug 
Administration and the Meteorological Administration of Korea, and divided 4 grades, interest(green), caution(yellow), warning(orange), risk(red).

In order to identify the usefulness of the proposed system, we experiment using tofu. Using the $900 \mathrm{MHz}$ smart RFID sensor tag, we measure the temperature and humidity data of surrounding environment of tofu. The data is applied food poisoning index, and expressed food poisoning grade. We compare grade with status of tofu using nose and eye. Through the experiment, we are confirmed that the propose system can prevent food poisoning.

\section{The Proposed System}

\subsection{The manufactured sensor tag}

A block diagram of the manufactured smart sensor tag is shown figure 1 . The tag is consisted of $900 \mathrm{MHz}$ antenna, RF front-end, power management, demodulation, modulation, MSP 430, and sensors. Power management supplies power to each of the parts. The power is collected from the RF energy. Demodulation transmits data converted RF data signal using ASK to MSP430. And modulation transmits digital signal of MSP430 to reader using the backscatter method. MSP430 checks reader activity and data management. Sensors convert temperature and humidity data to voltage. The manufactured smart sensor tag is passive type tag worked by RF signal power. Figure 2 is manufactured smart sensor tag [2].

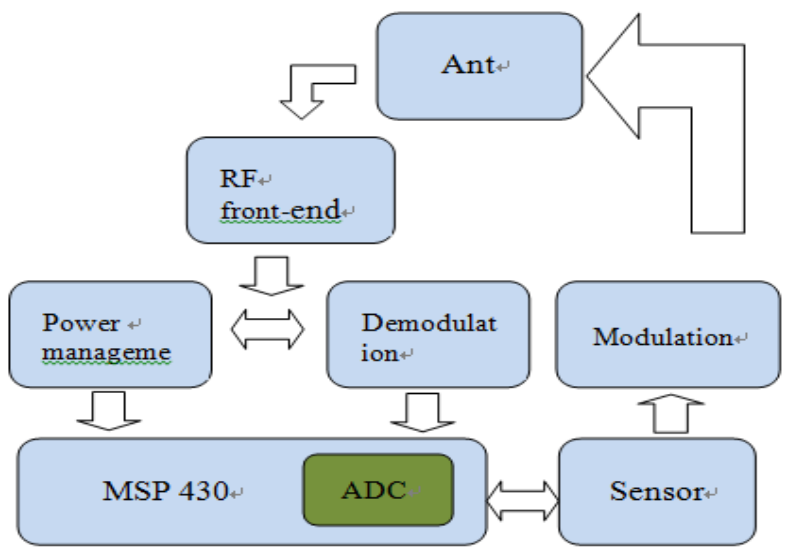

Figure 1. A block diagram of smart RFID sensor tag

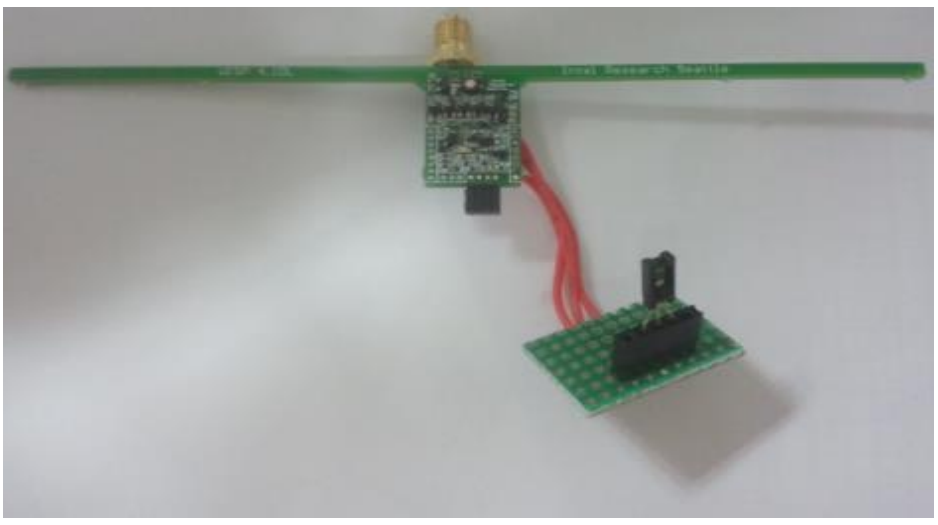

Figure 2. The manufactured sensor tag 


\subsection{Temperature Sensor}

Reader using the monitoring system is Speedway Revolution UHF RFID reader by IMPINJ. Figure 3 is shown the reader, and Table 1 is specification of reader.

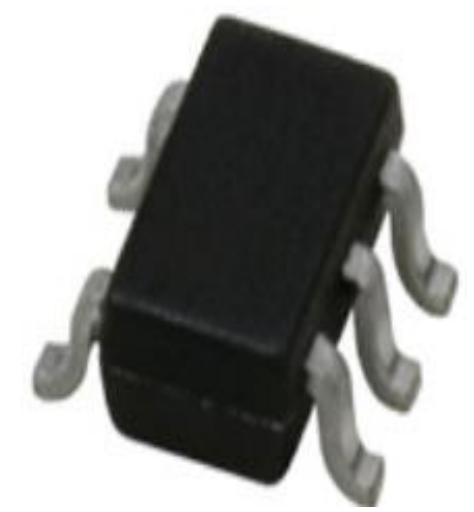

Figure 3. The temperature Sensor

The proposed system temperature sensor was used a commercial product which produced in the National Semiconductor. It shows in Figure 3. Characteristics of temperature sensor are shown in Table 1.

Table 1. Characteristics of temperature sensor

\begin{tabular}{cc}
\hline Characteristics & Content \\
\hline Supply Voltage & $1.5 \mathrm{~V}$ to $5.5 \mathrm{~V}$ \\
\hline Supply Current & $9 \mu \mathrm{A}$ \\
\hline Temperature Accuracy & $20^{\circ} \mathrm{C}$ to $150^{\circ} \mathrm{C} \quad \pm 2.7^{\circ} \mathrm{C}$ \\
\hline Operating Temperature & $-50^{\circ} \mathrm{C}$ to $150^{\circ} \mathrm{C}$ \\
\hline
\end{tabular}

\subsection{Humidity Sensor}

The proposed system Humidity sensor was used a commercial product. It shows in figure 4. Characteristics of temperature sensor are shown in Table 2.

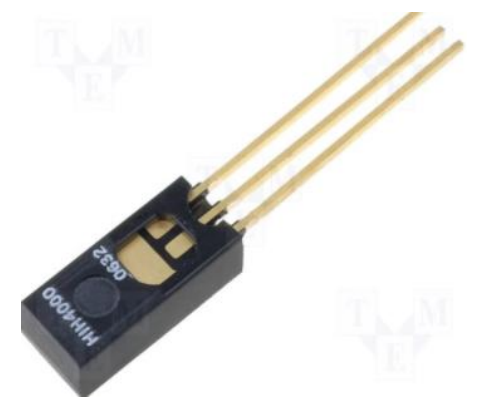

Figure 4. The humidity sensor 
Table 2. Characteristics of humidity sensor

\begin{tabular}{cc}
\hline Characteristics & Content \\
\hline Supply Voltage & $4 \mathrm{~V}$ to $5.8 \mathrm{~V}$ \\
\hline Supply Current & $200 \mu \mathrm{A}$ \\
\hline Humidity Accuracy & $\pm 3.5 \% \mathrm{RH}$ \\
\hline Operating Temperature & $-40^{\circ} \mathrm{C}$ to $85^{\circ} \mathrm{C}$ \\
\hline Operating Humidity & $0 \% \mathrm{RH}$ to $100 \% \mathrm{RH}$ \\
\hline
\end{tabular}

\subsection{The monitoring system}

Reader using the monitoring system is Speedway Revolution UHF RFID reader by IMPINJ. Figure 5 is shown the reader, and Table 3 is specification of reader.

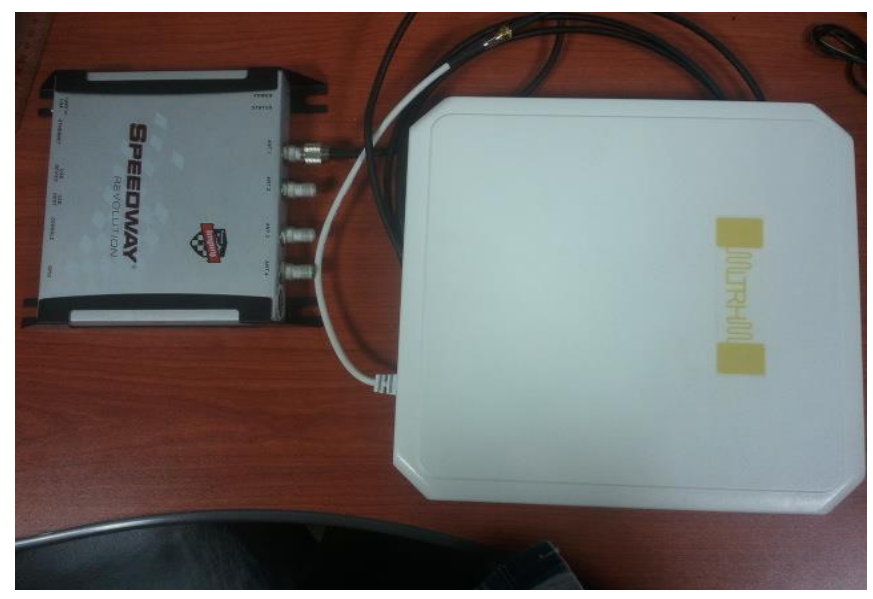

Figure 5. Reader

Table 3. Specification of reader

\begin{tabular}{cc}
\hline Contents & Range \\
\hline Interface Protocol & EPC global UHF Class 1 Gen 2 / ISO 18000-6C \\
RF Frequency & $900 \mathrm{Mhz} \sim 930 \mathrm{Mhz}$ \\
RF Range & $10 \mathrm{~cm} \sim 10 \mathrm{~m}$ \\
Transmit Power & $+10.0 \sim 30.0 \mathrm{dBm}$ \\
Power Consumption & $24 \mathrm{~V}$ \\
\hline
\end{tabular}

Food poisoning index is expressed possibility of food decomposition, which is based on temperature condition that affects growth of microorganisms as regards food decomposition with consideration of humidity condition, as a percentage. Figure 4 is shown food poisoning index that is provided the Food and Drug Administration and the Meteorological Administration of Korea. As in Figure 6, food poisoning index can be divided 4 grades, interest(green), caution(yellow), warning(orange), risk(red). Consumers apply the temperature and humidity information that is measured from sensor tag to Figure 4, can check the status of the food. 


\begin{tabular}{|c|c|c|c|c|c|c|c|c|c|c|c|}
\hline 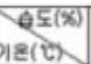 & 0 & 10 & 20 & 30 & 40 & 50 & 60 & 70 & 80 & 90 & 100 \\
\hline 0 & 282 & 225 & 29.9 & 89.4 & 29.9 & 10.5 & 81.2 & 320 & 330 & 341 & 35.4 \\
\hline 2 & 225 & 29 & 23.3 & 29.9 & 30.5 & $\pi .2$ & 820 & 32.9 & 34.0 & 35.3 & 36.7 \\
\hline 4 & 22.9 & 23 & 238 & 50.4 & 81.1 & 31.9 & 828 & 383 & 35.2 & 36.6 & 38.3 \\
\hline 6 & 20.3 & खो & 30.4 & ร1. & 31.9 & B2. & 89.8 & 35.1 & 365 & 391 & 40.0 \\
\hline 8 & 291 & 803 & 310 & $\pi .1$ & 321 & I5I & 350 & 36.4 & 820 & 399 & 420 \\
\hline 10 & 30.3 & 803 & 313 & 82.6 & 82. & 34.3 & 86.8 & 31.9 & 391 & 419 & 4.3 \\
\hline 12 & 80.9 & III & 125 & 116 & 348 & 36.1 & भI & 39.6 & 41.7 & 44.1 & 46.9 \\
\hline 14 & 31.6 & 325 & 315 & 347 & 36.0 & 18.5 & 39.4 & 41.5 & 439 & 45.6 & 49.8 \\
\hline 16 & 824 & 284 & 34.6 & क5. & 87.5 & 29.3 & 41.8 & 48.7 & 464 & 495 & 52.1 \\
\hline 18 & 233 & 345 & 35.8 & म.3 & 39.1 & 41.2 & 45.5 & 46.2 & 49.8 & 523 & 560 \\
\hline 20 & 844 & 857 & 372 & 59.0 & 41.0 & 413 & 460 & 49.0 & 52.5 & 565 & 603 \\
\hline 22 & 556 & 32.1 & 30.8 & 40.8 & 43.1 & 45.8 & 49.8 & 52.2 & 56.1 & 60.6 & 65.6 \\
\hline 24 & 870 & 897 & 407 & 429 & 45.5 & 42.5 & 519 & 55.8 & 602 & 652 & 70.7 \\
\hline 26 & 89.5 & 405 & 421 & 45.8 & 49.3 & 51.6 & 555 & 59.8 & 648 & 703 & 76.4 \\
\hline 28 & 40.3 & 42.6 & 45.1 & 40.0 & 51.4 & 55.2 & 59.5 & 64.4 & 69.8 & 759 & 82.7 \\
\hline 30 & 424 & 449 & 47.8 & 51.1 & 54.9 & 59.1 & 640 & 69.4 & 75.4 & 822 & 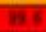 \\
\hline 32 & 447 & 4.6 & 50.8 & 545 & 50.8 & 69.6 & 689 & 74.9 & 81.6 & 31 & प्र11 \\
\hline 34 & 47.3 & 56.5 & 542 & 58.4 & 6.2 & 6.5 & 745 & 31.1 & 886 & 364 & Tin \\
\hline 36 & 50.3 & 539 & 58.1 & 62. & 61.1 & 740 & 805 & (13) & PII & 101 & Tix \\
\hline 38 & 53.6 & 57 & 524 & 58.5 & 75.5 & 60.0 & Na? & काइ & 100 & 100 & 100 \\
\hline 40 & 57.4 & 620 & 572 & 73.0 & 72.5 & MII & 825 & IN" & 100 & 100 & 1 in \\
\hline
\end{tabular}

Figure 6. The food poisoning index according to the temperature and humidity

\section{Experiment}

In order to identify the usefulness of the proposed system, we perform experiment using tofu. Figure 7 is experimental picture.

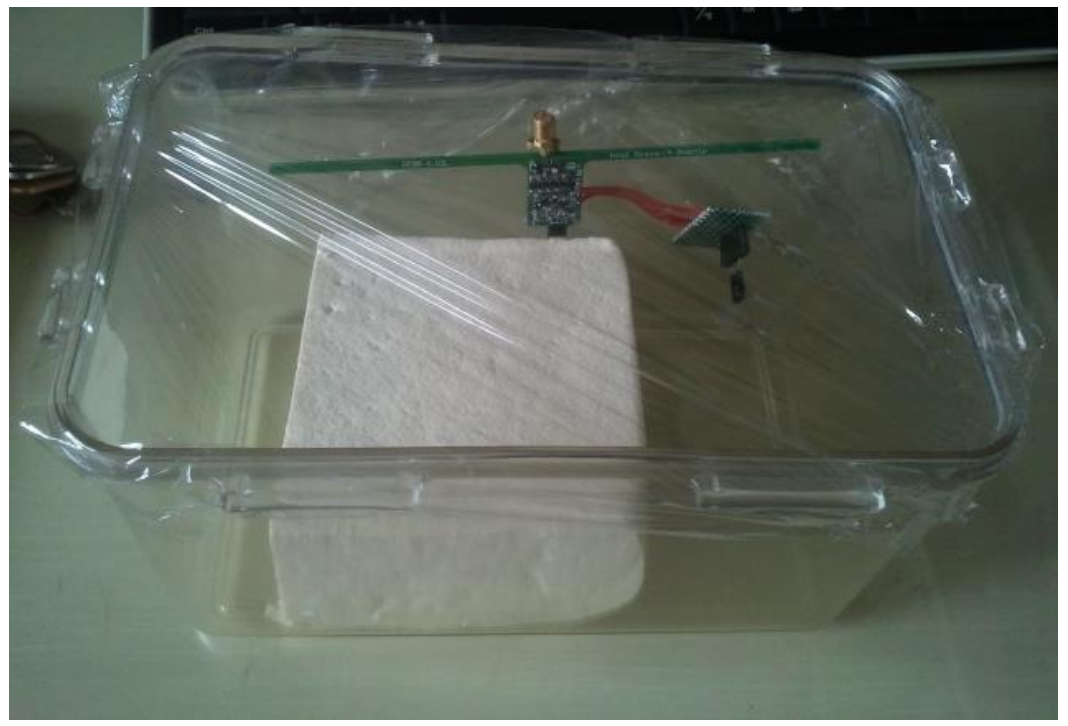

Figure 7. Experimental picture

As shown in Figure 7, tofu and sensor tag are putted into container, and sealed up plastic wrap. The smart sensor tag measure temperature and humidity in real time around tofu. The measured data is shown in Figure 8, and 9. 
International Journal of Multimedia and Ubiquitous Engineering

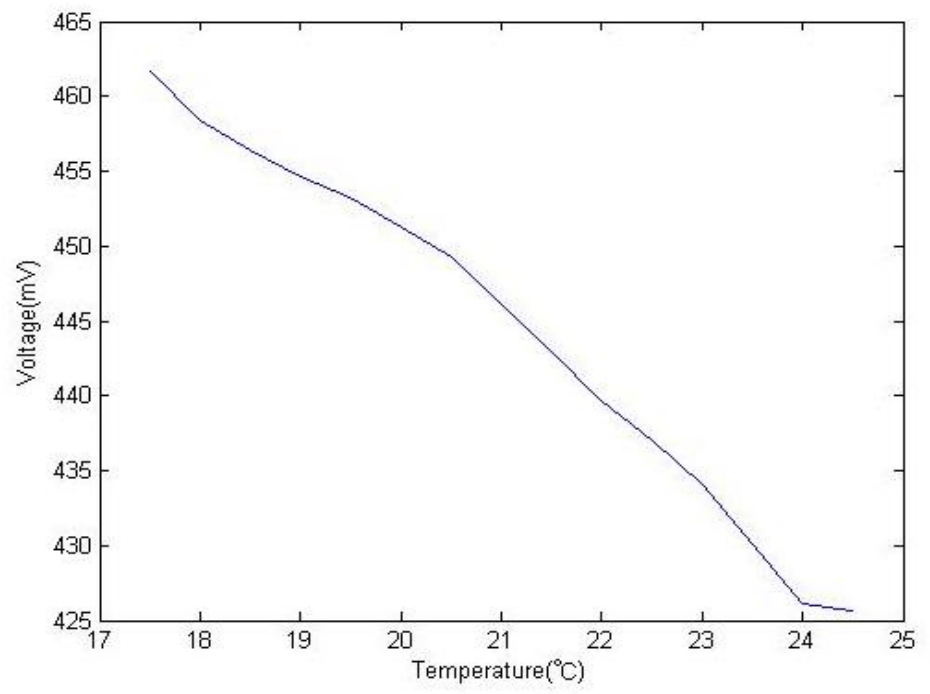

Figure 8. Output graph of temperature sensor

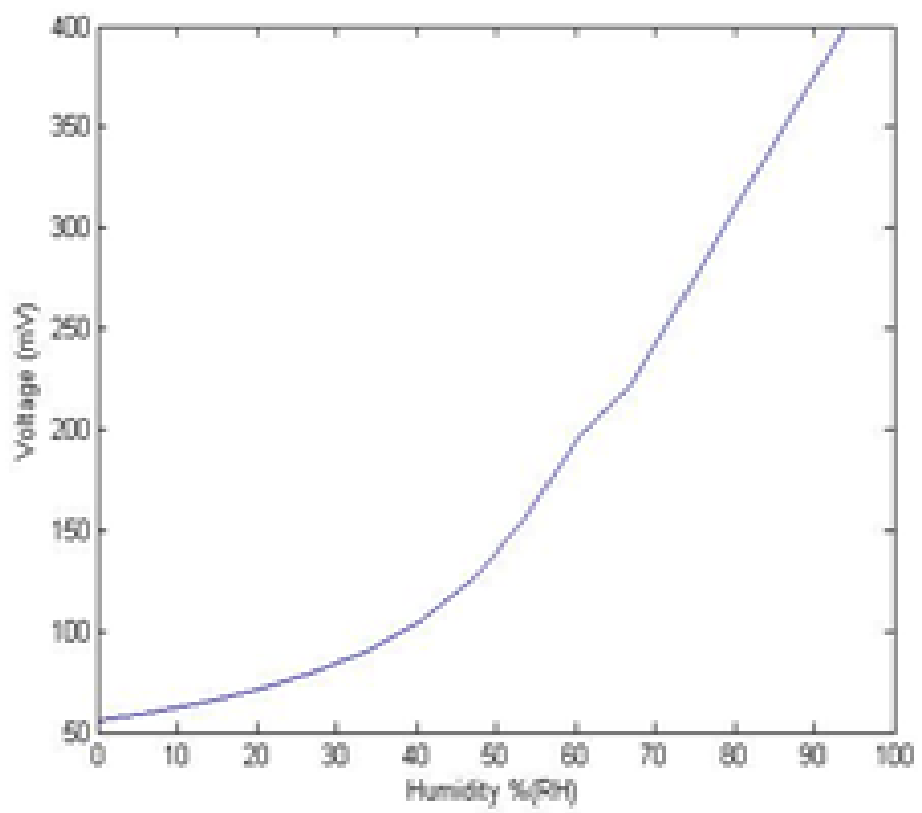

Figure 9. Output graph of humidity sensor

In Figure 8 and 9, we confirm that voltage is almost linearly changed in accordance with temperature and humidity. The result data is almost linear so we can easy to using it.

$$
\begin{gathered}
\text { Temperature }(\mathrm{C})=-0.19 * \mathrm{~V}(\mathrm{mV}) \\
\text { Humidity }(\%)=0.24 * \mathrm{~V}(\mathrm{mV})
\end{gathered}
$$

Equation 1 and 2 is derived by graph of Figure 8 and Figure 9. If we use this equation, we can know the temperature and humidity to see the output voltage. The suggested system 
output the voltage information in RFID reader. So we need to calculation the temperature and humidity using voltage information.

The temperature and humidity data measured from sensor tag is calculated suitable for food poisoning index. The calculated food poisoning index is displayed 4 grades, interest(green), caution(yellow), warning(orange), risk(red), and we can do check the status of food. Figure 10 is shown the test program expressed food status to food poisoning grade. In figure 10, food poisoning grade is displayed in red rectangular.

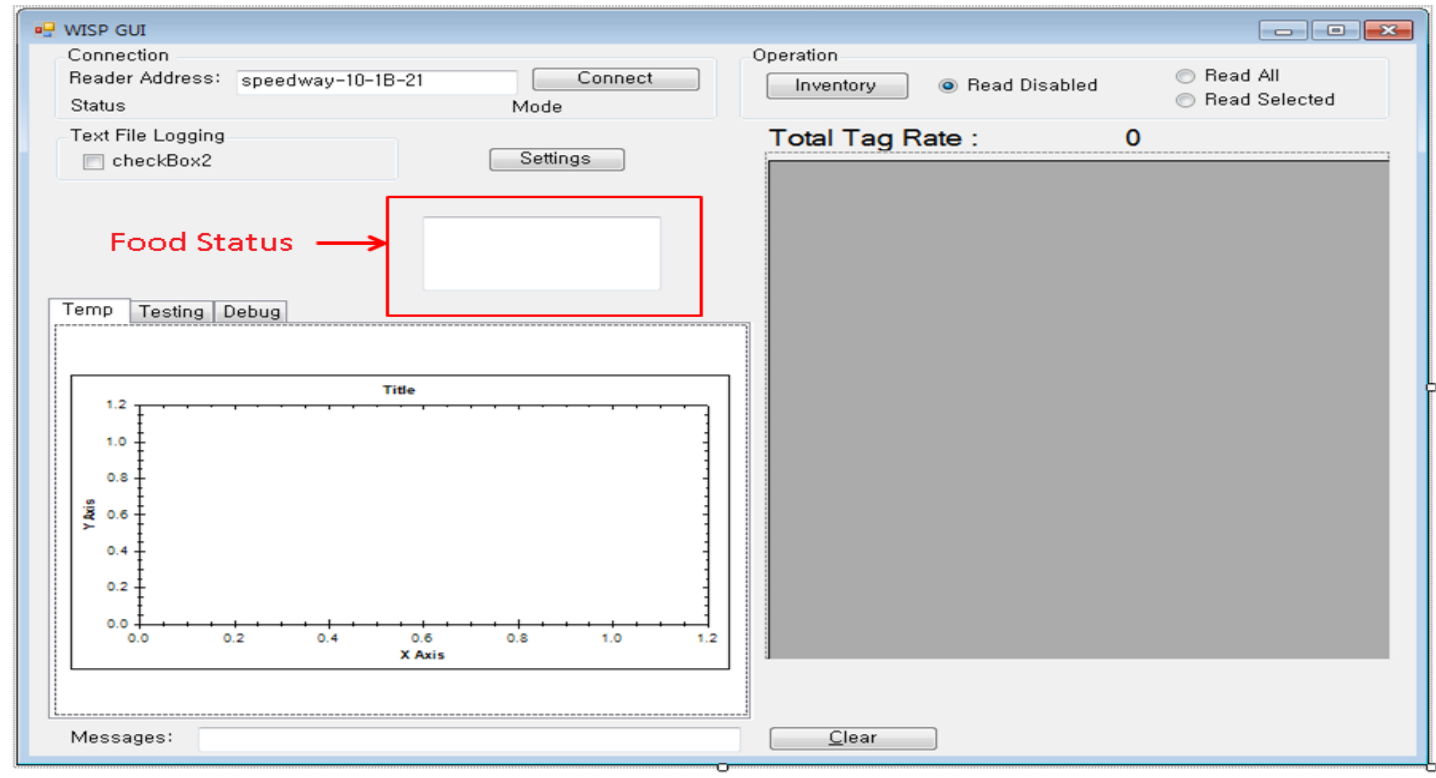

Figure 10. Test program

In this experiment, we measured temperature and humidity of around tofu, and applied to food poisoning grade. We compared food poisoning grade with food status using nose and eye, and confirmed the usefulness of the proposed system.

\section{Conclusion}

The human health harm factor that is occurred most often in the world is the disease which is caused by the contaminated food as food poisoning. A food contamination can occur a large part caused by the careless food handling because of improper temperature or humidity when a food is transporting and storing.

In this paper, we proposed the monitoring system that prevents food poisoning due to food contamination that can occur during the transportation and storage of food. Proposed system consists of RFID tag, temperature and humidity sensor, sensor interface, RFID reader, and server. The proposed system could prevent food poisoning through food status monitoring as the temperature and humidity data measured of surrounding environment during the transportation and storage of food in real time by $900 \mathrm{Mhz}$ smart RFID sensor tag, which was contained temperature and humidity sensor, was applied to food poisoning index that was provided the Food and Drug Administration and the Meteorological Administration of Korea, and divided 4 grades, interest(green), caution(yellow), warning(orange), risk(red).

In order to identify the usefulness of the proposed system, we performed experiment using tofu. Using the $900 \mathrm{MHz}$ smart RFID sensor tag, we measured the temperature and humidity 
data of surrounding environment of tofu. The data was applied food poisoning index, and expressed food poisoning grade. We compared food poisoning grade with status of tofu using nose and eye. Through the experiment, we were confirmed that the propose system can prevent food poisoning.

\section{Acknowledgements}

This research was supported by the Agriculture Research Center (ARC, 710003-03-1SB110) program of the Ministry for Food, Agriculture, Forestry and Fisheries, Korea.

\section{Reference}

[1] K. D. Kyeung, "Research for the presentation of food borne illness food service group, Food and Drug Administration Research Report, (2002).

[2] R. Want, "Enabling ubiquitous sensing with RFID”, Comput, vol. 37, no. 4, (2004) April, pp. 84-86.

[3] Alanson P. Sample, "Design of an RFID-Based Battery-Free Programmable Sensing Platform", IEEE Transactions on Instrumentation and Measurement, vol. 57, no. 11, pp. 2608-2615, (2008) November.

[4] http://www.impinj.com/Speedway_Revolution_UHF_RFID_Reader.aspx.

[5] http://www.kfda.go.kr/jsp/page/food_zone_life.jsp/seq=1.

\section{Authors}

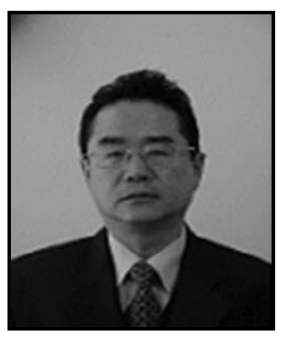

Ki-Hwan Eom was born in Seoul, Korea in 1949. He received the B.S. and Ph.D. degree in electronic engineering from Dongguk University, Korea in 1972, and 1986, respectively. He was a visiting professor from 1989 to 1990 at Toho University and from 2000 to 2001 at University of Canterbury. Since 1994, he has been with Dongguk University, where he is currently a professor in the Division of Electronics and Electrical Engineering. His research interests are in electronic application and convergence system.

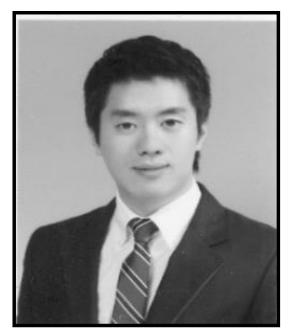

Chang Won lee received the B.S. degree in Department of Electronic Engineering from Dongguk University, Seoul, Korea, in 2011, where he is currently pursuing the M.S. degree. His research interests are RFID system, senser network and control engineering.

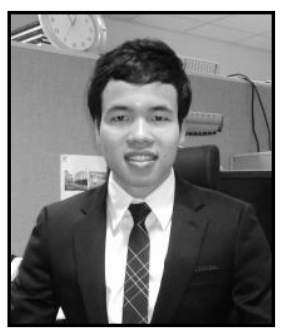

Nghia Truong Van received the B.S. degree in Automatic Control Engineering from Hanoi University of Technology, Vietnam, in 2010. And M.S. degree in Electrical and Electronics Engineering from Dongguk University, Seoul, Korea, in 2013.His research interests are RFID system, Automation system and Management System. 


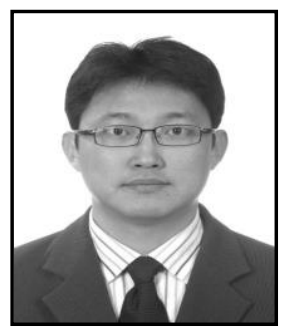

Kyung Kwon Jung was born in Korea. He received the B.S., M.S., and $\mathrm{Ph} . \mathrm{D}$. degrees in Electronic Engineering from Dongguk University, Seoul, Korea in 1998, 2000 and 2003, respectively. He is currently working as research engineer in Embedded Software Convergence Research Center at Korea Electronics Technology Institute. His research interests are in intelligent systems, digital signal processing and sensor network applications.

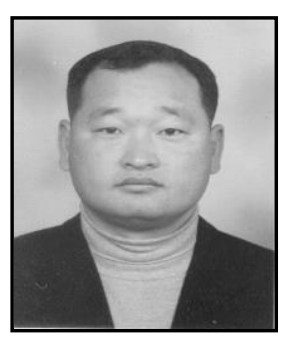

Joo Woong Kim received the B.S. degree in Electronics Engineering from Dongguk University, Korea in 1996 and Ph.D. degree from Dongguk University in 2003. He is currently is a professor of Public Health University of the computer electronics. His research interests in: Intelligent Systems, USN, SMPS.

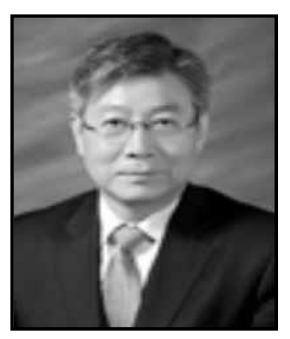

Woo Seung Choi was born in Seoul. He received the B.S. and Ph.D. degree in electronic engineering from Dongguk University, Korea in 1981, and 1994, respectively. He has been with Gachon University, where he is currently a professor in the College of Global General Education. His research interests are in Systems Engineering and Intelligent System. 
International Journal of Multimedia and Ubiquitous Engineering Vol.8, No.5 (2013) 